\title{
11. No Concretion without God
}

Palmyre Oomen (Nijmegen)

\section{Introduction}

The eleventh chapter of Whitehead's Science and the Modern World is concerned with "the puzzling fact that there is an actual course of events" (172). Whitehead calls this fact 'puzzling' because that actual course in itself is a concrete and limited fact, that metaphysically speaking might have been otherwise than it is. Thus, immediately after a chapter on "Abstraction," dealing primarily with possibilities, Whitehead wants to address in the present chapter the issue of "the concrete," i.e., that which has contingently grown together, which is none other than actual occasions and their actual course. And he entitles this chapter "God," in order to express his philosophical conviction that the explanation for the puzzling fact in question is God, for without God there can be no concretion.

My presentation and analysis of Chapter XI will focus on Whitehead's concept of an actual occasion as a twofold togetherness, on his concept of God as required for concretion, and on the interrelation between those two topics.

\section{Whitehead's Metaphysical Attitude}

Whitehead begins with a discussion of Aristotle, "the greatest metaphysician," an expression Whitehead uses primarily on account of the fact that Aristotle was "entirely dispassionate" inasmuch as he created a metaphysics without being influenced by ethical or religious interests. Thus, the only reason for Aristotle to introduce the concept of (God as) the Prime Mover was, according to Whitehead, none other than the metaphysical train of thought that led him to that concept without being influenced by religious interests (173).

Clearly, Whitehead's intention is to adopt a similar course of thinking. He too wants to be metaphysically dispassionate (PR 343). He too thinks that there is a metaphysical need for an entity at the base of all actual things. In Science and the Modern World, he calls this the required "Principle of Concretion" (174; also in Process and Reality: PR 244, 345) or a required "principle of limitation" (178), whereas in Adventure of Ideas, he will phrase his insight as: "The Platonic 'persuasion' is required" (AI 115). 
It is important to understand what Whitehead means by 'requirement.' It might sound as a 'God of the gaps' reasoning. However, Whitehead explicitly intends not to follow that erroneous way of arguing. Indeed, he chides Descartes precisely for using God as the big metaphysical 'exception' for no other reason than to save his metaphysical system. Without the metaphysical exception of God, Descartes' system was bound to disintegrate (PR 49, 190). Nevertheless, Whitehead too requires God in his metaphysics. What then is the difference? According to Whitehead, Descartes tries to avoid inconsistency by assuming that God has the function of sustaining the world, but he does so without being able to make intelligible from within his system why God should want to fulfill that function: "Descartes tells us that they [=the bodily substances] are sustained by God, but fails to give any reason why God should care to do so" (FR 30). Thus, Descartes places God outside the metaphysical system.

Whitehead too requires God but, contrary to Descartes, he gives formal reasons from within his metaphysical principles why God does what he does. This is why he so strongly emphasizes that God is the "chief exemplification' of the metaphysical principles, and not a stopgap to be used to save the collapse of metaphysical principles (PR 343).

\section{Aristotle's Prime Mover, Newton's Law of Inertia and Whitehead's Principle of Concretion}

Aristotle's postulation of a Prime Mover was based on a cosmology we now judge to be erroneous. In his view, special causes were required in order to sustain the motion of material things. However, Newton's famous Law of Inertia, also known as the First Law of Motion which states that every body continues in its state of rest or of uniform-motion-in-a-straightline, unless it is compelled to change that state by forces impressed upon it, proved this to be incorrect.

Nonetheless, Whitehead argues that, even though Aristotle's argument is formally incorrect, our generally accepted thinking suffers from a metaphysical problem that is analogous to the problem Aristotle raises, and that the solution to this problem must be analogous to Aristotle's solution. In Whitehead's words: "In the place of Aristotle's God as Prime Mover, we require God as the Principle of Concretion" (174). However, in order to understand this, we must first come to a better understanding of the problem. 


\section{The Actual Occasion as Twofold Synthesis}

In order to elucidate the metaphysical problem to which the Principle of Concretion is meant to provide the solution, we must examine the implications of Whiteheads ideas regarding an actual occasion and about the course of actual occasions. For Whitehead, every actual occasion fuses into unity the many elements that are offered to it. Such 'growing together' may be considered in two ways: as the achievement of a togetherness of all actual occasions, and as the achievement of a togetherness of eternal objects (175). How is this twofold synthesis to be understood?

The integration of past actual occasions into the new actual occasions may be compared with, for instance, something like the self-creation of a mosaic picture out of a certain available set of mosaic pieces (or to use an illustration with less substantivistic connotations: the self-composition of a piece of music from a certain set of tones). This, admittedly very inadequate, comparison may help elucidate the following two different but interdependent aspects.

On the one hand, the past actual occasions function as prehensible 'mosaic pieces' from which a new synthesis, the new 'mosaic,' will arise. However, even though each of those 'pieces' will inevitably occupy some place, the question 'how' (what kind of place) is still open. In other words, the entities are not synthesized into a merely unqualified aggregate. If that were the case, there could only be one creature, as Whitehead emphasizes (RM 90). Indeed, though each new composition, i.e., each new creature, accepts ("feels") the data given to it, the how of these feelings is not fully determined by the data themselves. The process of self-creation just entails the elimination of the indetermination of these 'hows' (in Whitehead's later terminology "the subjective forms" of these feelings). That is to say, the self-creation of an actual occasion requires that the 'how' of each feeling becomes definite in respect to the eternal objects with which feeling clothes itself (PR 85-86). And thus, on the other hand, the synthesis of the new creature may also be regarded as the harmonization of different 'hows,' that is to say of the eternal objects which determine how the entities are felt and integrated (cf. RM 90).

This enables us to understand that according to Whitehead, an actual occasion is the realization of a twofold "togetherness," a togetherness of actual occasions as well as of eternal objects (174). He calls the realization of such concrete synthesis - a realization due to decision, limitation, restriction - an attainment of "value" (94). Here, 'value' refers primarily to a certain pattern, that is to say, it refers to a definite concrete way in which all beings (both actual and ideal) are together within an actual occasion. 
The question which must now be addressed is, how such concretion actually takes place.

\section{Types of entry, and the "graded envisagement"}

The relationship of an actual occasion $a$ to an other occasion $b$, concerns the way $b$ is present in $a$, it concerns $b$ 's way of entry into $a$, as Whitehead says. Although the variety of types of ways in which other occasions can enter into a particular actual occasion $a$, that is to say, into the "experience which is $a$," is unfathomable, Whitehead distinguishes two fundamental types of such relationships (175). In the first type, the actual occasion $(a)$ is considered on the side of its full concreteness (cf. 170, 175-176), in the second, the occasion is also considered in respect to its cognitive experience. Thus, the first type concerns the actual occasion as merely a physical event, the second considers the actual occasion as a complete event, that is, as an event including its mental functioning (cf. 170-171, 176).

First fundamental type of entry. According to Whitehead, a full conceptual description of the real essence of an actual occasion is impossible. That is to say, the real essence of an actual occasion cannot completely be described by means of a finite abstractive hierarchy of eternal objects ('finite' in the sense that the abstractive hierarchy stops at a finite grade of complexity) (167-170). Indeed, the real essence of an actual occasion entails an infinite abstractive hierarchy of eternal objects (169). An infinite abstractive hierarchy also involves the spatio-temporal relations (of $a$ to the occasions entrant in $a$ ). Time and temporal differentiations are essential aspects of an actual occasion, which always exhibits itself as a process, as a becomingness. Thus, the types of entry of other actual occasions into the essence of $a$, may be differentiated according to different definitions of past, present, or future: The new occasion organizes itself from other occasions that collectively form its past (176). But, even when it is completely determined by its past, it forms itself as a new re-enactment in its present in relation to which it is completely free. And it forms itself in the light of its future: the synthesis in $a$ of eternal objects felt as notrealized and as requiring for their realization the passage from $a$ to subsequent actual occasions.

Second fundamental type of entry. This last reflection leads us to Whitehead's discussion of a second fundamental type of entry (which is especially important for the topic of this chapter, viz. the requirement of a Principle of Concretion). 
In his discussion of the first type of entry, Whitehead pays attention only to an actual occasion in its full concreteness (170). In his discussion of the second type of entry, he pays explicit attention to the fact that a complete occasion also includes occasions as remembered, or anticipated, or imagined, or thought. These "mentally" included elements can be characterized by the "abrupt" realization of finite eternal objects, which is to say that they can be exhaustively described by means of a finite complex concept (171). Such a description either involves a reference to the eternal objects describing the abstract essences of the entered actual occasions (entered, for instance, as remembered or as anticipated), or it involves a reference to these eternal objects in their relatedness to the other eternal objects that are not realized in that occasion (176).

This last remark needs some explanation. According to Whitehead: "[A]n actual event is an achievement for its own sake, a grasping of diverse entities into a value by reason of their real togetherness in that pattern, to the exclusion of other entities" (104). The exclusion here intended is an essential condition of value - "Restriction is the price of value" (178) and entails the link between value and finitude: "The infinite has no properties. All value is the gift of finitude which is the necessary condition for activity" (MG 674). 'Value' therefore always involves the inclusion of certain eternal objects and the exclusion of others. More accurately, this inclusion or exclusion of eternal objects regards the individual essences of these eternal objects (e.g., something is red, not blue) (159), but the inclusion of one eternal object $(A)$ qua individual essence (e.g., red) entails the inclusion of "the complete determinate relatedness of [that eternal object] $A$ to every other eternal object, or set of eternal objects" (e.g., the inclusion of 'red' entails the ingression of not-yellow, not-blue, color, extension, etc.) (162).

As a result of this determinate relatedness of the eternal object $A$ to every other eternal object, any ingression of $A$ into an actual occasion $a$ involves the graded realization of all other eternal objects in that same occasion according to their relationships to $A$ (cf. 161). Therefore, every eternal object is in some sense ingredient in each occasion. An eternal object is either ingredient as what it is in itself, that is as "individual essence" (159), or it is indirectly ingredient through its "relational essence," that is, by its relationships to those eternal objects that are individually included (160). Thus, an eternal object $B$ may, in virtue of its individual essence be excluded from a particular aesthetic synthesis, so that its presence in the event is but an "unfulfilled alternative" (162). But Whitehead also leaves room for gradations between total inclusion and total exclusion of eternal objects in respect of their individual essence. Such intermediate 
possibilities are said to be alternatives that, though unfulfilled, are as such nevertheless aesthetically relevant. Such is the case, for instance, in examples taken from art, literature, or criticism based on unfulfilled ideals, where the important role of precisely non-realized possibilities may appear in various ways (158-159, 162; PR 185).

Thus, even though each individual actual entity is what it is in virtue of exclusion, the value of such entity, its realization of a pattern, can be stipulated only by involving its (complex) relations to all entities: "Each actual entity is an arrangement of the whole universe, actual and ideal, whereby there is constituted that self-value which is the entity itself" (RM 98). And again: "An organism is the realisation of a definite shape of value. The emergence of some actual value depends on limitation which excludes neutralising cross-lights. Thus an event is a matter of fact which by reason of its limitation is a value for itself; but by reason of its very nature it also requires the whole universe in order to be itself' (194).

In the case of the mental phenomena mentioned above - like memory, anticipation, imagination, or thought - , the realization of the finite eternal objects involved entails, as we have seen above, the "full sweep of eternal relatedness," i.e., the relatedness to all eternal objects, in various gradations of realization. Whitehead terms this "realized extension of eternal relatedness" (which is here an "abrupt realization") the "graded envisagement" which each occasion prehends into its synthesis (176).

The inclusion of this graded envisagement is what makes a new occasion 'feel' (a term used by Whitehead in Process and Reality) possibilities of togetherness. By providing a feeling of what (in one sense) is not-being, the graded envisagement is the source of error, but also of truth, art, ethics, and religion. The inclusion of this graded envisagement confronts fact with alternatives (176-177).

Having said this, Whitehead pursues his explanation in a text in which he characterizes the envisagement as a conditioning of the synthesizing activity, and then further analyzes this conditioning or limiting, and concludes that, apart from other forms of limitation, an antecedent limitation among values is required. Then, in order to make this conceivable, Whitehead postulates a principle of limitation as an "attribute" of the substantial activity, and bluntly states that "God is the ultimate limitation" (178).

This very condensed line of thought will now be the subject of a far more detailed discussion. 


\section{The late introduction of 'God': God as the supreme ground for limitation}

In the last part of Chapter XI, Whitehead analyzes the requirements for a metaphysical understanding of the puzzling fact that there is an actual but contingent course of events. Previously, in Chapter VI (which unlike Chapter XI is based on the original text of the Lowell Lectures) Whitehead had already considered the general flux of events, and there his analysis had led him to speak of an "underlying eternal energy" or "underlying activity" to which he attributed three types of envisagement: "These are: first, the envisagement of eternal objects; secondly, the envisagement of possibilities of value in respect to the synthesis of eternal objects; and lastly, the envisagement of the actual matter of fact which must enter into the total situation which is achievable by the addition of the future" (105). Thus, in the text of Chapter VI Whitehead attributes "the envisagement of possibilities of value" to the nature of the underlying activity, and elaborates this as follows: "[I]n the nature of the eternal activity there must stand an envisagement of all values to be obtained by a real togetherness of eternal objects, as envisaged in ideal situations. Such ideal situations, apart from any reality, are devoid of intrinsic value, but are valuable as elements in purpose" (105). Contrary to the text of Chapter XI analyzed above (176177) in which the inclusion of graded envisagement is related to error, truth, art, ethics, religion and alternatives, but not to purpose, here in the 'earlier' text, Whitehead does link envisagement of possibilities directly to values and purpose, as indeed he will also do in his later Process and Reality where this thought is taken up again and further elaborated. Considering the fact that, when in Process and Reality Whitehead discusses God's primordial nature - the source of the initial purpose of each new event - , he explicitly refers to the "graded envisagement" paragraph from Chapter XI (176-177), I think we are justified to conclude that the SMW 176-177 paragraph also connotes the aspect of value and purpose. Moreover, this would clarify the otherwise obscure transition in the Chapter XI text from a reference to "graded envisagement" to standards of value as principle of limitation to a reference to God as the supreme ground for limitation.

Now, let us take a closer look at the text following 176-177, that is, at the text of 177-178. Whitehead's paragraph begins with the following statement: "This general concept, of an event as a process whose outcome is a unit of experience, points to the analysis of an event into (i) substantial activity, (ii) conditioned potentialities which are there for synthesis, and (iii) the achieved outcome of the synthesis" (177). Whitehead seems to argue that because each event is a novel event, the past occasions are 
"conditioned potentialities" waiting to be synthesized (ii). However, because the synthesis of those conditioned potentialities also requires the ingression of eternal objects, he adds in a passage a few lines below that "[t]he envisagement which enters into the synthesis is also a character which conditions the synthesising activity" (177).

Whitehead then continues with a thorough analysis of the notion of limitation. As we have mentioned above, Whitehead is convinced that the becoming of an actual occasion is directly due to limitation or exclusion. $\mathrm{He}$ conceives actuality as in essential relation to an unfathomable possibility: it is "a limitation imposed on possibility" (174). In other words, concretion as the becoming of actuality requires a limitation with respect to the indefinite plurality of possibilities. To quote Ivor Leclerc: "[It] entails a definite limitation of possibility to 'a this,' which entails a standard in terms of which that limitation is effected." This explains that in his search for a principle of concretion, Whitehead in chapter XI comes to speak of a 'principle of limitation' or of the 'supreme ground for limitation.'

So, Whitehead's analysis of limitation is of the utmost importance for our topic. Apart from the trivial limitation of particulars (each mode is this and not that), Whitehead distinguishes two main limitations with regard to individualization, viz. a limitation of antecedent selection (concerning logical and causal relationships and the particularity of the actual course of events) (177), and an antecedent limitation regarding values. The latter limitation means that " $[\mathrm{t}]$ here cannot be value without antecedent standards of value" (178). This claim is based on the consideration that such antecedent standards of value are needed in order to discriminate the acceptance or rejection of the diverse possibilities that can be actualized (178).

And this leads Whitehead to remark that: "Thus as a further element in the metaphysical situation, there is required a principle of limitation" (178). The text itself does not make clear whether this principle is the ground of both the "limitation of antecedent selection" and of the "limitation among values" or only of the latter, but the remainder of the chapter strongly suggests that Whitehead is interested primarily in the latter (even though in the end this distinction may prove to be futile ${ }^{2}$ ). Whitehead jumps, in a not overly transparent way, from "[T]here is required a principle of limitiation" (178), to the statement "[W]e must provide a ground for limitation which stands among the attributes of the substantial activity. This attribute provides the limitation for which no reason can be given: for all reason flows from it. God is the ultimate limitation" (178), and then again at the end, to the conception of God "as the supreme ground for limitation" (179). Thus, even though he never says so explicitly, there is the inevitable 
suggestion that Whitehead sees God as the required principle of concretion in virtue of his being a principle of limitation, and, more precisely, of his being the supreme principle of (or ground for) limitation. ${ }^{3}$

We have seen already that Whitehead speaks of a "graded envisagement (of eternal objects)" which is, among other things, a source of alternatives for the novel actual occasion (176-177). Now Whitehead conceives God as a principle of limitation which, as an antecedent limitation among values, introduces contraries, grades, and oppositions, and enables discrimination in the acceptance or rejection of possibilities (178). Whitehead does not say anything explicitly about the relationship between the function of principle of limitation and the function of envisagement, although there is the suggestion that they in fact coincide. As John Cobb sees it: "This envisagement [of eternal objects] is not something additional to his function as principle of limitation, but it explains how that principle operates," for: "the way in which God functions as the principle of limitation is by ordering the infinite possibilities of the eternal objects according to principles of value." ${ }^{4}$ Cobb's interpretation is based on ideas derived from Whitehead's later work, especially Process and Reality. And, as I have argued above, Whitehead justifies this by providing an explicit link to SMW 176-177 in a text on the divine primordial nature in Process and Reality (PR 189).

\section{The nature and the working of this principle of limitation: An essay in elucidation by some imaginative leaps}

The purpose of what follows is to offer an interpretation of this principle of limitation, by making use of some texts from Process and Reality and especially by making some comparisons with more mathematically based examples.

The principle of limitation or of concretion which the text of Chapter XI speaks of, together with the idea of the graded envisagement of the eternal objects, comes back in Process and Reality as one of the ways in which Whitehead refers to God's so-called "primordial nature" (PR 164, 244, $345)$, which he describes as "the unconditioned conceptual valuation of the entire multiplicity of eternal objects" (PR 31). To this last phrase, he adds: "By reason of this complete valuation, the objectification of God in each derivate actual entity results in a graduation of the relevance of eternal objects to the concrescent phases of that derivate occasion" (PR 31, italics added). Similar remarks may be found in a number of other passages. Thus, he writes: "In this sense God is the principle of concretion; namely, he is 
that actual entity from which each temporal concrescence receives that initial aim from which its self-causation starts. That aim determines the initial gradations of relevance of eternal objects for conceptual feeling" (PR 244, italics added). And in yet another passage: "The limitation whereby there is a perspective relegation of eternal objects to the background is the characteristic of decision. Transcendent decision includes God's decision. He is the actual entity in virtue of which the entire multiplicity of eternal objects obtains its graded relevance to each stage of concrescence" (PR 164, italics added). And again: "[...] the primordial nature of God, which is his complete envisagement of eternal objects" (PR 44, italics added).

From these and other texts one may safely conclude that the graded envisagement of possibilities, the valuation of possibilities, the antecedent limitation by standards of value, the principle of limitation and God as primordial nature are all closely interconnected, and that there is an intimate kinship between the prehension of the graded envisagement (featuring also, as we have argued above, aspects of value and purpose) and the prehension of God's primordial nature which provides the initial aim. In what follows we will make use of this connection in a further exploration of the nature and function of God as principle of limitation in relation to the concrete and contingent flux of events.

In speaking of a valuation of all possibilities, Whitehead does not mean an absolute valuation of the possibilities (in the sense that, for instance, red would be absolutely good, or green absolutely bad), but a relative valuation, that is to say, a valuation of the possibilities in relation to every possible initial state of a new event, in other words, in relation to every possible set of entities available for integration in a new occasion. This is why Whitehead speaks of a "relative relevance" (PR 344). In SMW too, he says explicitly that the envisagement of values does not signify an intrinsic value: "Such ideal situations, apart from any reality, are devoid of intrinsic value" (SMW 105).

Simply put, what Whitehead means by God's ordering of possibilities according to relative relevance may be read as follows: if, in a given situation, the possibilities $A, B, C, D$ and $E$ present themselves as prehensible, then, given this combination, $A$ may best be valued in this way, $B$ in that way etc., so as to achieve a synthesis with a maximum effect of aesthetic intensity, whereas in relation to another possible supply of possibilities the valuation for $A, B$ etc. will be different. Thus, all possibilities have a specific valuation in relation to every possible supply of possibilities. 
Harking back to the above given example of the mosaic may give some access to what Whitehead means by such ordering. ${ }^{5}$ For instance, given a certain supply of many mosaic stones, the best possibility of realization into a mosaic (in other words, the manner of prehending into synthesis that yields the highest aesthetic intensity) is, for example: letting the little green pieces form the foreground pattern while keeping the remainder of the stones for a mixed background (cf. PR 164) (which is something like the 'graded envisagement' of our text - SMW 176). But, given another combination of available pieces, the best possibility of synthesis is, for instance: give a foreground function to the red and yellow little stones and spread all the green stones among all the remaining ones diffusely into the background. Thus a valuation is conceivable of all possibilities in relation to every possible supply of possibilities, that is, a valuation of possibilities in relation to each other.

This elucidation may be presented somewhat more formally by making use of the image of a mathematical function $\mathrm{F}$ attaching (mapping) a specific $y$ to every possible $x .^{6}$ In this image the letter $\mathrm{F}$ signifies obviously mutatis mutandis - the divine principle of limitation or of concretion, which is the unchanging valuative ordering of all potentialities in respect of each other: if $x_{1}$ then $y_{1}$, if $x_{2}$ then $y_{2}$ etc. The $x$ signifies the variable possible initial situation of an actual occasion (the possible "actual world") being composed of many data to be synthesized, and the $y$ stands for the 'the most valuable possibility for synthesis of these data' ( $c f$. what is called the "initial aim" in PR 244, and the "graded envisagement which each new occasion prehends into its synthesis" in SMW 176).

Thus, mathematically expressed, $\mathrm{F}$ is to be seen as something that more or less resembles an optimization function. It is important to emphasize that both $x$ and $y$ stand for possibilities: respectively, the possible initial situation containing a multiplicity of data, and the best possibility for synthesis of these data. Thus, F ('the divine principle of concretion'), in a valuative optimizing way, relates potentialities to each other. It should also be noted that this $\mathrm{F}$ itself is atemporal and unchanging (Whitehead's term "valuation" corresponds to my ' $\mathrm{F}$ '), whereas the $y$, the initial aim or "graded envisagement," is temporal and changing in relation to, and in dependence on the $x$ (Whitehead's term 'evaluation' corresponds to this temporal y). In 'Immortality,' his last publication, Whitehead expresses this as follows: "But Evaluation [cf. the $y$ ] always presupposes abstraction from the sheer immediacy of fact [cf. the $x]$ : It involves reference to Valuation [cf. the $\mathrm{F}] .{ }^{, 7}$

This mathematical image may be helpful in elucidating how God, as principle of limitation, as the relative valuation of all potentialities, can 
influence the worldly processes: given a certain initial state (a certain $x$ ), God's valuation (the function $\mathrm{F}$ ) delivers the best combinatory possibility for that case (a particular $y$ ). And the nascent event feels this aim in prehending this "graded envisagement." But please note that in Process and Reality $y$ is not the actual outcome, not the actual next step, but only the starting point, the initial aim of the new event, "from which its selfcausation starts" (PR 244).

Let us now, in the light of the above, go back to our text of Chapter XI. Here Whitehead argues that the general modal individualization is limited in two ways. The first sort of limitation is a limitation by the actual course of events, "which might be otherwise so far as concerns eternal possibility, but is that course" (177). This limitation takes three forms - logical conditions, causal conditions, and particularization - which Whitehead summarizes as "limitation of antecedent selection." I suggest that this stands for the $x$ in the above given mathematical analogy.

The second sort of limitation is limitation by conformation to a standard. Restriction is the price of value ('value' here in the sense of being something concrete, a concrete pattern of togetherness). There cannot be 'value' (in the sense of a concrete individual content of a variable possibility - $c f$. the expression "the variable $x$ has the value 5") without an antecedent standard of value that enables discrimination in the acceptance or rejection of different possibilities. My suggestion is that this standard of value is - very roughly - represented by the $F$ in the above given mathematical analogy, where $\mathrm{F}$ resembles an optimization function that relates possibilities to possibilities, indicating what in a concrete situation is the most valuable option.

For the purpose of getting a better 'feeling' for the 'interactive' way in which such mathematical function operates in relation to concrete processes, a brief excursion may be useful here. Let us compare (again with all the shortcomings that are inherent to examples) the principle of concretion with an interactive computer program (e.g., a football or a computer assisted drawing (CAD) program). ${ }^{8}$ The program is a complex but unchangeable 'algorithm' (a file on your hard disc) that allows for an infinite variety of concrete courses the game may take. The player's choices determine what specific situation will emerge, the computer file has no foreknowledge of that situation, but its reaction will always provide 'the best possible option.' The program file is a possibility structure: for each possible situation, it has a correspondingly optimal option. And because the 'best possibility' it provides is contingent upon a concrete situation occasioned by the user of the program, the efficacy of the program is eminently 'interactive.' Clearly therefore, in spite of the constancy of the 
program, the course of the game is never fixed from the outset. Every new course will be different.

The divine principle of concretion may be compared, mutatis mutandis, to such computer program inasmuch as, like the computer program, it is both immutable and ignorant of the situations that will present themselves, yet it always offers the 'best possibility' for every given contingent situation. And as no game can be played without the program, so too there can be no world without the divine principle of concretion.

Finally, I would like to take the example just one step further by comparing for the sake of the argument God's role as principle of concretion with the role of a 'criterion function' in adaptive systems.' Adaptive self-organizing processes are processes that develop and change their internal structure adaptively in relation to their respective environment. Such processes often involve an implicit criterion, such as a criterion of minimum energy use, or of optimal mutual distance, or of maximum benefit. For instance, biological evolution involves a 'fitness function,' which expresses the different fitness values of the many possible genotypes of a species in relation to the environment. In natural systems such 'criterion function' is not external to the system, it expresses the immanent fact that, given a certain kind of environment, one solution fits better (produces more fertile offspring, for example) than another. Complex self-organizing processes often involve such 'criterion function' (or 'credit assignment algorithm' to use John Holland's term ${ }^{10}$ ) as an immanent valuation principle. That is to say, such processes involve something that discriminates a development in one direction as more attractive than a development in a different direction, so that one is felt to be more beneficial than the other. And this difference in attractiveness comes to give an orientation to the course of the process.

This function or algorithm is mostly hidden because in natural processes it operates in an immanent way. In artificial processes however, the criterion function must be invented and built in as the condition for the operation of the system. Thus, an artificial intelligence device, a learning robot, for example, requires the explicit creation and implementation of a 'fitness function' that, in the form of a computer program, functions as a valuation principle distinguishing better from worse solutions. ${ }^{11}$ My suggestion therefore is that Whitehead's concept of the principle of concretion may be understood as somewhat similar to such fitness function. ${ }^{12}$ And this suggestion seems to nicely concur with Whitehead's remark that: "Mere blind appetition would be the product of chance and could lead nowhere. [...] There is a discrimination of appetitions according to a rule of fitness" (FR 89-90). 


\section{By way of conclusion}

Whitehead's metaphysical train of thought led him in Chapter XI of Science and the Modern World to the conclusion that a Principle of Concretion is required. But he insists that he wants this claim to derive from metaphysics itself: "For nothing, within any limited type of experience, can give intelligence to shape our ideas of any entity at the base of all actual things, unless the general character of things requires that there be such an entity" (173-174). In this 'dispassionate attitude' he feels a kinship with Aristotle: "[Aristotle] was entirely dispassionate; and he is the last European metaphysician of first-rate importance for whom this claim can be made" (173). Like Aristotle who, though starting from a cosmology that is now considered erroneous, argues the necessity of a Prime Mover, so Whitehead, starting from a contemporary cosmology, analogously argues the necessity of a Principle of Concretion. According to Whitehead, this principle is required in order to be able to account for the general implications of the course of actual occasions (174).

The analysis has shown that this requirement is intrinsically related to the two perspectives from which an actual occasion is to be considered, respectively, as the achievement of a togetherness of all actual occasions, and as the achievement of a togetherness of eternal objects (175). These two perspectives correspond, respectively, to the questions 'What does the occasion create itself from?' and 'How does the occasion create itself?' (which in some sense may be compared with Aristotle's matter and form distinction). The former perspective refers to other actual occasions, the latter to eternal objects or, more specifically, "to an envisagement of all values to be obtained by a real togetherness of eternal objects" (105). The duality appears again when Whitehead argues that, next to a limitation of antecedent selection, an antecedent limitation among values is required. It brings him to the conclusion, that as a further element in the metaphysical situation, there is required a "principle of limitation," which he ultimately signifies as "God."

In the previous section, where by some imaginative leaps I have endeavored to elucidate the text of Chapter XI, I have expressed the conviction that the image of a mathematical function, especially in the form of an optimization function or a criterion function (fitness function), is to some extent analogous with Whitehead's ideas on God as principle of concretion or limitation.

The comparison may clarify several paradoxes regarding God as principle of concretion (or, in terms of Process and Reality, God as primordial) in relation to the world. It may clarify that, as such, God is immutable and 
nevertheless is the ground for the changeability of the world; that God is a definite matter of fact and nevertheless the condition for the contingent course of the actual world; that God is without (fore)knowledge of the world and nevertheless provides every worldly situation with the optimal option for its concretion; that God does not participate in the 'game' of the world, and nevertheless is a necessary condition for the becoming and the course of the concrete world by distinguishing better from worse solutions.

For Whitehead, there is no doubt that without such principle of limitation, no particular 'how,' no particularization of the course of actuality is conceivable. As he sees it, this leaves us with only two possible choices: Either we deny the reality of actual occasions as different from each other and we consider the actual concrete course of events as an illusion, or we admit to a metaphysics that allows for such principle, and we thus give credit to the contingency and the reality of the multifarious evolving world. Whitehead clearly opts for the latter alternative (178).

Finally, Whitehead's adoption of a principle of concretion at the base of all actual things should not be understood as implying the assertion that this principle explains everything. Indeed, Whitehead thinks such idea would be foolish. For God as principle of limitation may be a necessary condition, but does not provide a sufficient explanation. For, evidently, the ' $F$ ' (the principle of limitation) does not yield anything without a reference to some particular ' $x$ ' (the concrete antecedent course of events). Whitehead refuses to pay God the metaphysical compliment (or insult) of being the sole source of the world and of its actual course. Certainly, one of the reasons for this refusal is that he wants to avoid making God responsible for all good and all evil. Contrary to the classical conception according to which God is made to be the creator of everything, Whitehead conceives God as the supreme ground for the division between Good and Evil (179). The comparison with something like an optimization or criterion function as elaborated in the previous section may contribute to a better understanding of how a preferential distinction between better and worse options makes possible "the puzzling fact" of the occurrence of a contingent actual course of concrete events. 


\section{Bibliography}

Cobb, Jr., John B., A Christian Natural Theology: Based on the Thought of Alfred North Whitehead, Philadelphia: Westminster Press, 1965.

Heylighen, F., 'The Science of Self-Organization and Adaptivity,' 1999, $<$ http://pespmc1.vub.ac.be/Papers/EOLSS-Self-Organiz.pdf $>$.

Holland, John H., Hidden Order: How Adaptation Builds Complexity, Reading, Mass.: Perseus (Helix Books), 1996.

Kauffman, Stuart A., At Home in the Universe: The Search for Laws of Self-Organization and Complexity, New York etc.: Oxford University Press, 1995.

Leclerc, Ivor, 'The Problem of God in Whitehead's System,' in: Process Studies 14 (1985) 4, 301-315. Now also available online: <www.religiononline.org/showarticle.asp?title $=2571>$

Oomen, Palmyre M.F., 'Consequences of prehending God's consequent nature in a different key,' in: Process Studies 27 (1998) 3-4, 329-331.

Oomen, Palmyre M.F., 'Divine "Second Order" Design and Natural SelfOrganization,' in: Studies in Science and Theology: Yearbook of the ESSSAT 8 (2002), 3-16.

Oomen, Palmyre M.F., 'Immanence and Divine Persuasion: Whitehead's Provocative View on the Laws of Nature,' in: G. Debrock (ed.), Process Pragmatism: Essays on a Quiet Philosophical Revolution, Amsterdam etc: Rodopi Press, 2003a, 87-102.

Oomen, Palmyre M.F., 'On Brain, Soul, Self, and Freedom: An Essay in Bridging Neuroscience and Faith,' in: Zygon: Journal of Religion and Science (ed. by Philip Hefner), 38 (2003b) 2, 377-392.

Whitehead, Alfred North, Science and the Modern World, New York: Free Press, 1967. (1e ed. 1925). (=SMW).

Whitehead, Alfred North, Religion in the Making, New York: Meridian, 1960. (1e ed. 1926). (=RM).

Whitehead, Alfred North, The Function of Reason, Boston: Beacon Press. (=FR).

Whitehead, Alfred North, Process and Reality: An Essay in Cosmology, New York: Free Press, 1978 (Corrected edition, ed. by D.R. Griffin \& D.W. Sherburne). (1e ed. 1929). (=PR). 
Whitehead, Alfred North, Adventures of Ideas, New York: Free Press, 1967. (1e ed. 1933). (=AI).

Whitehead, Alfred North, 'Immortality,' in: P.A. Schilpp (ed.), The Philosophy of Alfred North Whitehead, New York: Tudor, 1951, 682-700. (1e ed. 1941).

\section{Notes}

${ }^{1}$ Ivor Leclerc 1985.

${ }^{2}$ After reading section 7 it may become obvious that this is an improper question. In the light of that section one may argue that the limitation of antecedent selection and the antecedent limitation among values correspond or go hand in hand with, respectively, the $x$ and the $\mathrm{F}$ in the proposed mathematical analogy. If this interpretation is accepted, it appears that $x$ cannot be seen independently from F. This is related to the fact that Whitehead holds a process view in which the advance of time is an essential part of the picture. This entails that the data of the actual world from which the novel event forms itself $(x)$, were themselves becoming events at an earlier moment, at which time they too came to be under the influence of the limitation by virtue of the antecedent standards of value, that is, under the influence of God as principle of limitation (F). Therefore, far from being a selfsubsisting factor that would be independent from $\mathrm{F}$, the $x$ itself became dependent on the same $\mathrm{F}$ (and, of course, on an previous $x$ ). Hence the limitation by antecedent selection cannot be seen as disconnected from the antecedent limitation among values.

${ }^{3}$ This means that in the remainder of the text the expressions 'principle of concretion' and 'principle of limitation' will be considered to be logically equivalent.

${ }^{4}$ Cobb 1965, 145-146.

${ }^{5}$ Cf. Oomen 2003a, 97.

${ }^{6} \mathrm{Cf}$. Oomen 1998, 330; 2003a, 97.

${ }^{7}$ Whitehead [1941]1951, 685.

${ }^{8}$ Cf. Oomen 2002, 11.

${ }^{9}$ The more usual technical term for such 'criterion function' is 'fitness function,' an expression that is not confined to the context of 
biological fitness alone. However, in order to avoid serious misunderstanding, I prefer to use in the text the more neutral expression 'criterion function.' A fitness function may be understood as a mathematical representation of freedom and direction, it is a mapping rule that basically assigns a direction (attractiveness, preference) to a set of eligible possibilities, thereby enabling a process to organize itself adaptively. For more information about fitness functions and their place in adaptive systems, see e.g. Kauffman 1995, Holland 1996, Heylighen 1999.

${ }^{10}$ Holland 1996, 87.

${ }^{11}$ Heylighen 1999, 23.

${ }^{12}$ Cf. Oomen 2003b, 384. 